\title{
Synthesis of a bulk nanostructured metastable Al alloy with extreme supersaturation of $\mathrm{Mg}$
}

\author{
Jae-Kyung Han ${ }^{1}$, Klaus-Dieter Liss $\mathbb{D}^{2,3}$, Terence G. Langdon ${ }^{4}$ \& Megumi Kawasaki ${ }^{1}{ }^{\text {* }}$ \\ Nanostructuring of bulk metals is now well documented with the development of severe plastic \\ deformation (SPD) for improving the physical and mechanical properties of engineering materials. \\ Processing by high-pressure torsion (HPT), which was developed initially as a grain refinement \\ technique, was extended recently to the mechanical bonding of dissimilar metals during nanostrcturing \\ which generally involves significant microstructural heterogeneity. Here we introduce, for the first \\ time, a bulk metastable Al-Mg supersaturated solid solution by the diffusion bonding of separate Al and \\ Mg metal solids at room temperature using HPT. Exceptional hardness was achieved homogeneously \\ throughout the metastable alloy with a record maximum supersaturated Mg content of $\sim 38.5$ at.\% \\ in the Al matrix having a grain size of $\sim 35-40 \mathrm{~nm}$. Our results demonstrate the synthesis of a bulk \\ nanocrystalline metastable alloy with good microstructural stability at room temperature where such \\ bulk solids are not yet reported for mechanical alloying by powder metallurgy.
}

An understanding of the principles and the technical parameters of many different SPD techniques has provided an opportunity to introduce superior mechanical properties and additional functionalities in nanostructured materials $^{1-4}$. Among the available SPD techniques, HPT is recognized as one of the most attractive methods since significant grain refinement is anticipated by comparison with other SPD procedures and often the technique is effective for hard-to-deform materials even at room temperature ${ }^{5}$. Utilizing this benefit, a new approach to mechanical bonding by HPT was examined recently for the synthesis of bulk hybrid nanostructured alloys by layering dissimilar nanostructured metals ${ }^{6-8}$ and ultimately leading to metal matrix nanocomposites by forming a reinforcement of a few nano-scale intermetallic phases ${ }^{9-14}$. In practice, this procedure applies the conventional HPT technique concurrently on two or more different kinds of bulk metals. The microstructures in the mechanically bonded metal systems by HPT processing generally develop into heterostructures ${ }^{15}$ involving heterogeneous and gradient microstructures from the sample surfaces to the depth. Thus, no clear information is available currently on any microstructural saturation and an ultimate metal state, thereby effectively limiting the mechanical properties when mechanically bonding dissimilar metals by HPT after very severe deformation. In this study, $\mathrm{Al}$ and $\mathrm{Mg}$ disks were mechanically bonded at room temperature by HPT for shear strains up to 4,000 through 100 torsional turns to assess the asymptotic microstructure by applying the simple yet powerful method of X-Ray diffraction (XRD) peak profile analysis.

Figure 1 shows the cross-sections of the Al-Mg disks (upper) after HPT for 1 turn as an example displaying the typical bonded sample ${ }^{9}$ and for 100 turns with the micrographs taken by a transmission electron microscope (TEM) at the disk center and edge (center) and a color-coded contour hardness map for the material after 100 HPT turns (lower). From the cross-section after 100 turns, it is apparent that there is no evidence of a Mg-rich phase across the disk diameter of the severely deformed material where the Mg-rich phase in the bonded material tends to appear in a darker color at the mid-plane as seen in the 1-turn sample. The current HPT procedure maintained a constant volume of material without any significant change during 1 to 100 turns by HPT, thereby implying the presence of reasonably consistent volume fractions of $\mathrm{Mg}$ in the Al-Mg system after HPT from 1 to 100 turns. It should be noted that segregation and a crack are visible at the lower left of the severely processed disk but this occurred during the molding and cutting after the HPT processing.

\footnotetext{
${ }^{1}$ School of Mechanical, Industrial and Manufacturing Engineering, Oregon State University, Corvallis, OR, 97331, USA. ${ }^{2}$ Materials and Engineering Science Program, Guangdong Technion - Israel Institute of Technology, Shantou, Guangdong, 515063, China. ${ }^{3}$ Technion - Israel Institute of Technology, Haifa, 32000, Israel. ${ }^{4}$ Materials Research Group, Department of Mechanical Engineering, University of Southampton, Southampton, SO17 1BJ, UK. *email: megumi.kawasaki@oregonstate.edu
} 


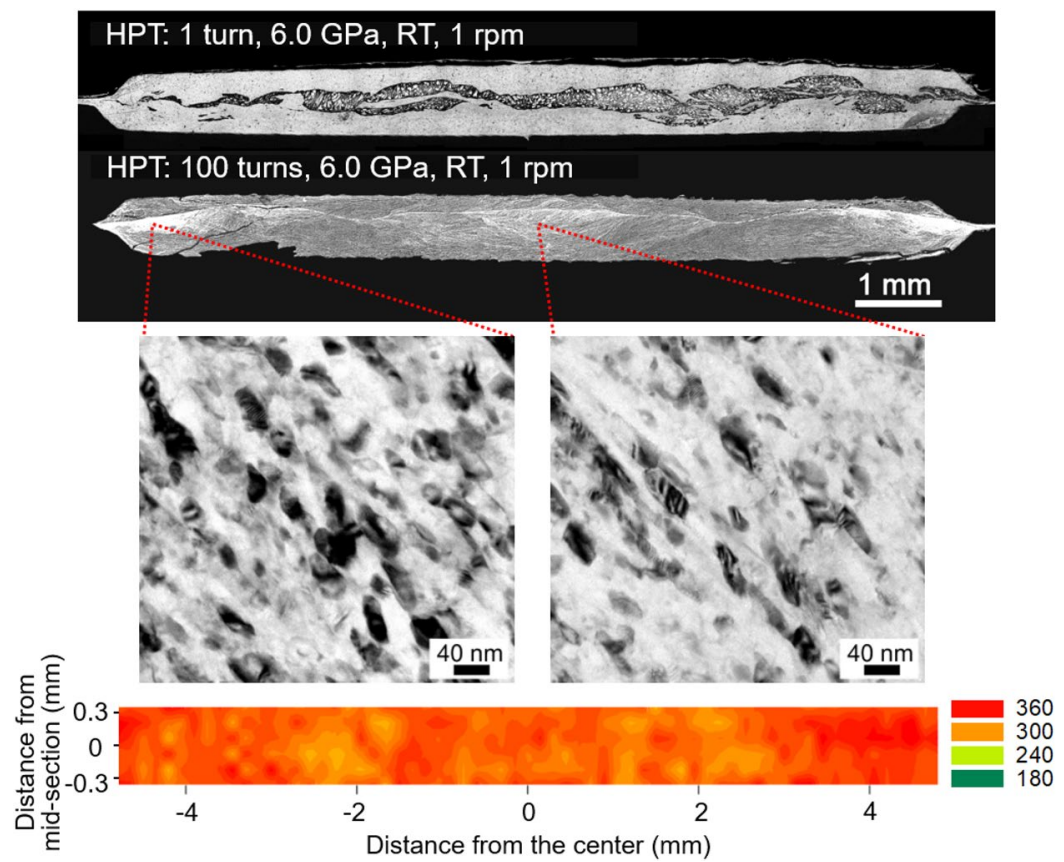

Figure 1. Deformed microstructure and the exceptional hardness of an Al-Mg system after HPT. The upper micrographs show the cross-sections of the Al-Mg disks after HPT for 1 turn as an example of mechanical bonding ${ }^{9}$ and 100 turns. In the center, the TEM micrographs taken at the disk center and edge prove microstructural homogeneity with grain sizes of $\sim 35-40 \mathrm{~nm}$ throughout the disk material. A colorcoded contour hardness map with a set of unique color keys that denote values from 180 to 360 provide the homogeneous hardness distribution with an average of 340 across the Al-Mg disk after $100 \mathrm{HPT}$ turns.

The microstructural homogeneity is visible by the TEM micrographs where there is a consistent nano-scale microstructure with equiaxed grains with grain sizes of $\sim 40 \mathrm{~nm}$ and $\sim 35 \mathrm{~nm}$ at the center and edge of the disk after $100 \mathrm{HPT}$ turns, respectively. The corresponding selected-area electron diffraction (SAED) patterns at both the disk center and edge (Extended Data Fig. 1) show spot-distributions on Debye-Scherrer rings indicating the polycrystalline aspect of ultrafine grain sizes within the illuminated volume, indexed solely as 111, 200, 220 and 331 reflections of an $f c c$ structure corresponding to Al. There are no diffraction spots indicating the presence of hcp $\mathrm{Mg}$ and any intermetallic phases, such as $\mathrm{Al}_{3} \mathrm{Mg}_{2}$ and $\mathrm{Al}_{12} \mathrm{Mg}_{17}$, in the diffractograms. In addition, these TEM observations provide little evidence for the existence of deformation twinning in the bulk $\mathrm{Al}-\mathrm{Mg}$ alloy.

The Vickers microhardness distribution over the vertical cross-section demonstrates a reasonably homogeneous hardness distribution within the material, thus confirming the microstructural homogeneity after HPT for 100 turns on the Al-Mg alloy. In practice, an average hardness of $H_{v} \approx 340$ and a maximum hardness of $\sim 370$ were recorded within the disk. Comparing the general saturated hardness ranges of $\sim 65$ for a commercial purity aluminum Al-1050 and 105 for the magnesium ZK60 alloy after HPT, the processing through 100 turns introduced an extreme hardness of the mechanically-bonded Al-Mg alloy. The results provide the first demonstration of a homogeneous microstructure and hardness distributions within a disk material produced by mechanical bonding through HPT. Thus, the microstructural homogeneity contrasts with earlier reports for the $\mathrm{Al}-\mathrm{Mg}^{8-10}, \mathrm{Al}^{-\mathrm{Cu}^{6,7,12}}$, $\mathrm{Mg}-\mathrm{Zn}^{13}$ and steel-vanadium ${ }^{16}$ systems.

A compositional analysis was conducted through TEM at both the center and the edge of the bonded $\mathrm{Al}-\mathrm{Mg}$ material. Figure 2(a,b) shows the representative scanning tunnel microscope electron microscopy (STEM) images with the marks describing the examined locations of Spectrums 1-3 at the disk center and Spectrums 4-6 at the disk edge, respectively, and the associated chemical compositions at the measured locations are listed in Table 1. The corresponding energy dispersive X-ray (EDS) spectra are also available (Extended Data Fig. 2). Widely scattered Mg contents were observed depending on the arbitrarily selected locations. Nevertheless, all locations showed exceptionally high contents of $\mathrm{Mg}$ in the $\mathrm{Al}$ matrix at room temperature and the detected maximum $\mathrm{Mg}$ content was 38.44 at.\% which is extremely high by comparison with the solubility limit of $\mathrm{Mg}$ of $\sim 1$ at.\% in $\mathrm{Al}$ at room temperature.

The X-ray diffraction (XRD) line profiles for the mechanically bonded Al-Mg alloys are available in earlier reports where these studies show the diffraction peaks of an $\mathrm{Al}_{12} \mathrm{Mg}_{17}$ intermetallic compound ${ }^{9,10}$. Accordingly, the XRD line profiles are shown in Fig. 3 with the scattering vector, $Q$, for, from the bottom, the initial Al sample in the as-received condition, an Al disk processed by HPT for 5 turns, the Al-Mg system immediately after HPT for 100 turns and Al-Mg processed by HPT for 100 turns followed by natural aging at room temperature for 60 days. From the XRD line profiles, it is possible to reach the following three conclusions.

Firstly, the Al-Mg system both after 100 turns by HPT and after natural aging shows consistent diffraction peaks for a pure $f c c$ structure, such as 111,200, 220 and 331, thereby demonstrating a fully Al-based solid solution without any trace of $h c p \mathrm{Mg}$ or intermetallic phase. Since the material contains a supersaturation of $\mathrm{Mg}$ at room 

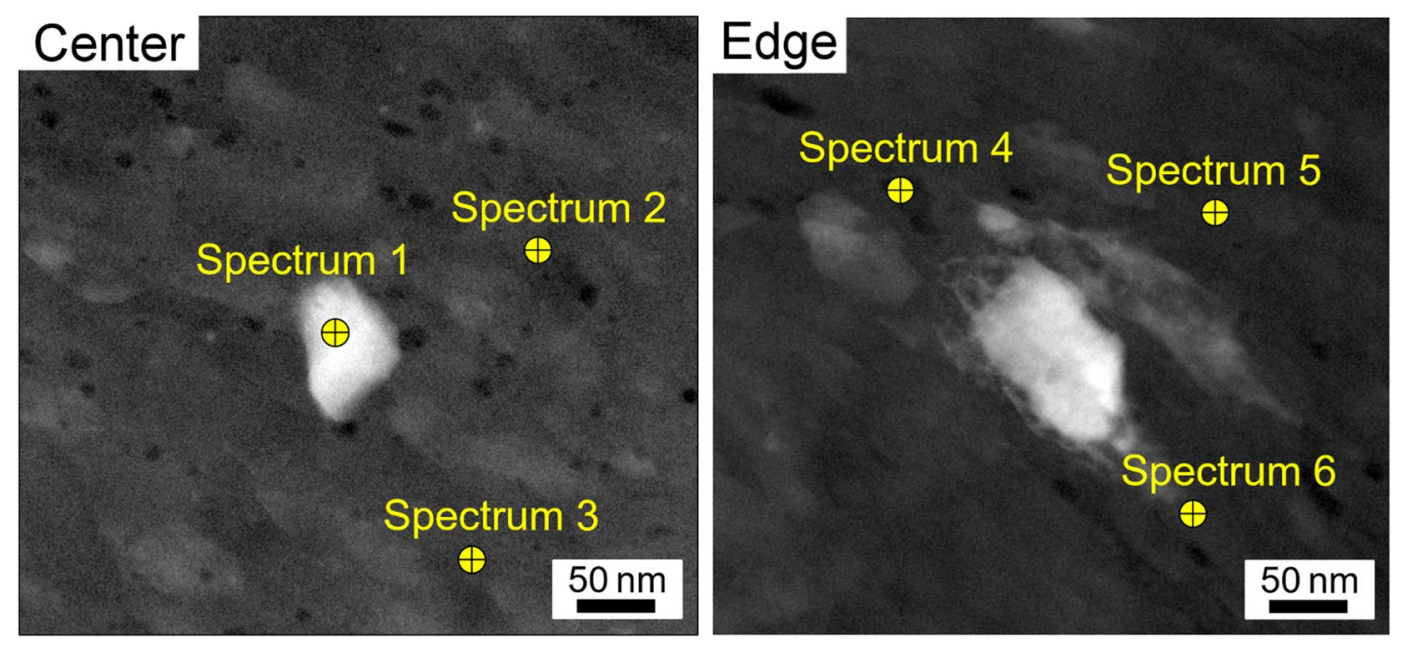

Figure 2. Representative STEM images for the Al-Mg system after HPT. These images are taken from the center and edge of the Al-Mg disk after HPT for 100 turns. The marks describing the examined locations of Spectrums $1-3$ and $4-6$ from the center and edge regions, respectively.

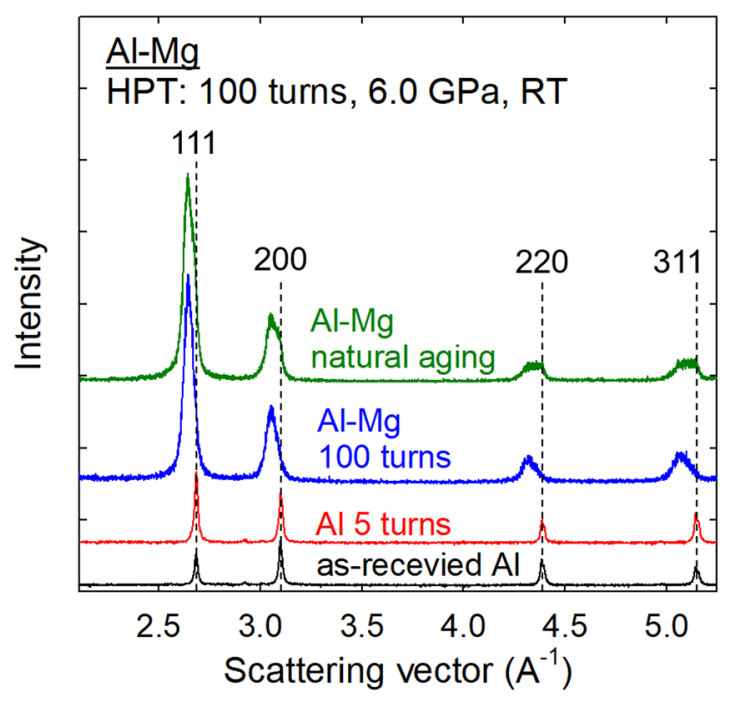

Figure 3. Representative X-ray diffraction profiles. These were taken from a disk surface of the Al-Mg system after HPT for 100 turns and after natural aging. Comparison with the reference XRD profiles for an as-received $\mathrm{Al}$ and the $\mathrm{Al}$ after HPT for 5 turns suggests that the Al-Mg system after HPT for 100 turns and after natural aging for 60 days has a pure $f c c$ structure with significant peak shifting influenced by grain refinement and compositional straining.

\begin{tabular}{|l|l|l|l|l|l|l|}
\hline \multirow{7}{*}{} & \multicolumn{6}{l|}{$\begin{array}{l}\text { Chemical composition (atomic\%) at the specific } \\
\text { measurement location (Spectrum) }\end{array}$} \\
\cline { 2 - 7 } & $\mathbf{1}$ & $\mathbf{2}$ & $\mathbf{3}$ & $\mathbf{4}$ & $\mathbf{5}$ & $\mathbf{6}$ \\
\hline $\mathrm{Al}$ & 94.43 & 65.83 & 74.24 & 61.56 & 84.82 & 87.59 \\
\hline $\mathrm{Mg}$ & 5.57 & 34.17 & 25.76 & 38.44 & 15.18 & 12.41 \\
\hline
\end{tabular}

Table 1. Chemical compositions measured at center and edge of the Al-Mg disk after HPT for 100 turns. The compositions of $\mathrm{Al}$ and $\mathrm{Mg}$ are examined at the six specific locations denoted in Fig. 2. The units are in atomic percent.

temperature, these results indicate that the mechanically-bonded Al-Mg system ultimately forms a nanostructured metastable ${ }^{17}$ alloy in a supersaturated solid solution state of $\mathrm{Al}$ after processing by HPT for 100 turns. This compositionally metastable material in a supersaturated solid solution state is maintained stable without any decomposition of a second phase during natural aging for 60 days at room temperature. 


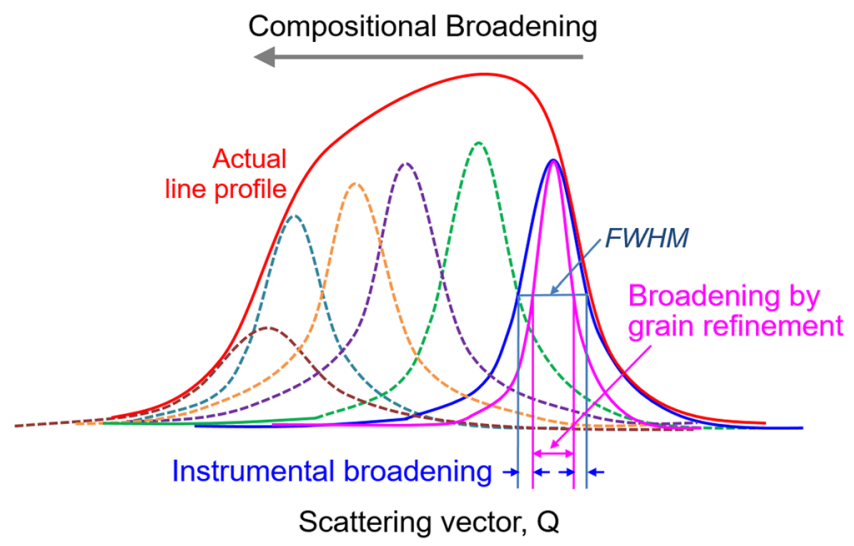

Figure 4. Schematic illustration of the peak broadening in an XRD line profile. This is due to the different components of compositional and instrumental broadening and broadening by grain refinement.

Secondly, the nanostructured metastable Al-Mg alloy immediately after HPT for 100 turns and after natural aging show significant shifting of the diffraction peaks to lower scattering angles by comparison with the regular peak locations for pure $\mathrm{Al}$ indicated by the vertical broken lines in Fig. 3 where there is no change in the peak position between the as-received $\mathrm{Al}$ and the $\mathrm{Al}$ after $5 \mathrm{HPT}$ turns. Thus, a large expansion of the $\mathrm{Al}$ lattice is anticipated in the metastable materials due to the supersaturation of Mg. Similar peak shifts were reported earlier not in bulk metals but in mechanically alloyed powders produced by ball milling of Al-40 at. $\% \mathrm{Mg}^{18,19}$. A further analysis by Materials Analysis Using Diffraction (MAUD) computed the mean lattice parameter of the metastable Al-Mg alloy as $a=4.1125 \AA$. Based on Vegard's law ${ }^{20,21}$, and considering an experimental study on the lattice widening by $\mathrm{Mg}$ solutes in $\mathrm{Al}^{22}$, the following relationship was obtained for estimating the $\mathrm{Mg}$ solubility, $X_{\mathrm{Mg}}$, in at.\% in Al by comparison with the lattice parameter of pure $\mathrm{Al}, a_{0}=4.049 \AA^{23}$.

$$
X_{M g}=9.045\left(\frac{a-a_{0}}{a_{0}}\right) \pm 0.003
$$

Thus, Eq. (1) gives an estimated average concentration of $\mathrm{Mg}$ in the $\mathrm{Al}$ matrix throughout the entire disk of 14.2 at.\%. This value is remarkably high when using a route involving a bulk-state reaction without applying an elevated processing temperature.

Thirdly, the XRD peaks are significantly broadened for the HPT-induced metastable Al-Mg alloy and in addition the aged material shows these peaks in a plateau configuration which becomes more apparent at the higher scattering angles. This broadening is attributed not only to grain refinement but also to an instrumental broadening due to inherent imperfections in the camera and recording devices and compositional straining where solute atoms expand or compress the matrix lattice ${ }^{24}$. Regarding the large and non-Lorentzian shaped total peak profile due mainly to the distribution of chemical strain where a schematic illustration is shown in Fig. 4 , the Williamson-Hall method breaks down to extract a small grain size broadening. Instead, a plateau-shape with a sharp fall-off profile was observed at $\Delta a / a_{0}=0$ or $X_{\mathrm{Mg}}=0$ in the metastable solution after aging. However, a tail exists beyond the $\mathrm{Al}$ edge to larger scattering vectors or negative strain values which can be attributed to size-broadening. Fitting only the high- $Q$ tail to a Lorentzian, a consistent grain size may be estimated from all four reflections. Thus, from a combination of many different peaks, it is reasonable to take the outline of the apparent line profile at the highest scattering vector indicating the smallest lattice parameter which is close to pure Al with a constrained state. Accordingly, the folding of the line fits well with a Lorentzian function ${ }^{25}$ and permits a convolution of a resultant line profile ${ }^{26}$. By performing this analysis, the line broadening of this specific high- $Q$ tail of the line profile incorporates the instrumental and grain refinement components without any compositional gradient broadening.

The analyzed data are summarized in Table 2 for the apparent full width at half maximum (FWHM) of the overall line profile with plateau, the FWHM of the unfolded line profile, instrumental broadening estimated on $\mathrm{a} \mathrm{LaB}_{6}$ from NIST using a similar set-up ${ }^{27}$, the FWHM for the actual grain refinement broadening and the computed crystallite sizes for the four plane reflections of 111,200, 220 and 311. It is apparent that the instrumental broadening in the present study may have only a limited influence on the overall FWHM at each coordinate. Moreover, the overall FWHM is significantly larger than the actual broadening by the reduced grain sizes and thus the metastable Al alloy after natural aging exhibits significant compositional broadening. The crystallite sizes of $\sim 25-34 \mathrm{~nm}$ were estimated after the deconvolution of the line broadening where the line broadening by grain refinement is anticipated as independent of the magnitude of the scattering vector. The result is reasonably consistent with the TEM observations taken at both the center and edge of the Al immediately after HPT for 100 turns as shown in Fig. 1 while the actual grain size of the aged material is expected to be slightly larger than this crystallite size. Nevertheless, it is reasonable to conclude that the nanostructured metastable $\mathrm{Al}$ is capable of retaining a consistent grain size for at least two months of natural aging at room temperature. 


\begin{tabular}{|l|l|l|l|l|l|}
\hline $\begin{array}{l}\text { Plane } \\
\text { coordinate }\end{array}$ & $\begin{array}{l}\text { FWHM } \\
(\text { overall })\left(\AA^{-1}\right)\end{array}$ & $\begin{array}{l}\text { FWHM } \\
\text { (the unfolded line profile })\left(\AA^{-1}\right)\end{array}$ & $\begin{array}{l}\text { Instrument broadening } \\
\left(\mathbf{L a B}_{6} \text { from } \text { NIST }^{27}\right)\left(\AA^{-1}\right)\end{array}$ & $\begin{array}{l}\text { Actual grain refinement } \\
\text { broadening }\left(\AA^{-1}\right)\end{array}$ & $\begin{array}{l}\text { Crystallite } \\
\text { size }(\mathbf{n m})\end{array}$ \\
\hline 111 & 0.0699 & 0.027 & 0.0064 & 0.020 & 30.0 \\
\hline 200 & 0.0821 & 0.029 & 0.0062 & 0.023 & 27.2 \\
\hline 220 & 0.1085 & 0.024 & 0.0059 & 0.018 & 33.5 \\
\hline 311 & 0.1381 & 0.030 & 0.0056 & 0.025 & 25.0 \\
\hline
\end{tabular}

Table 2. The apparent FWHM of the overall line profile with plateau, FWHM of the unfolded line profile, instrumental broadening based on $\mathrm{LaB}_{6}$ from NIST ${ }^{27}$, FWHM for actual grain refinement broadening and the computed crystallite sizes for four plane coordinates of 111, 200, 220 and 311.

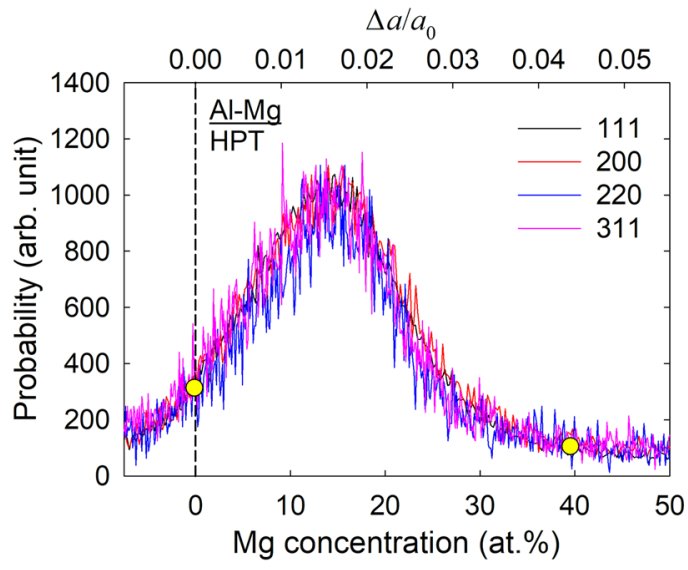

(a)

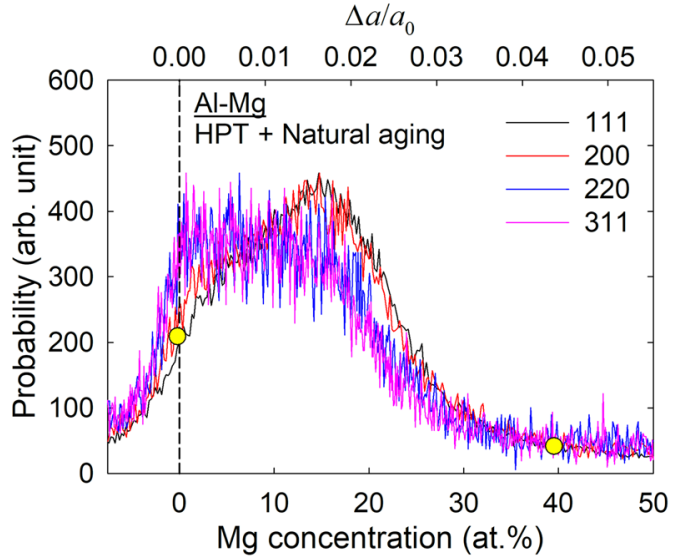

(b)

Figure 5. Estimation of the $\mathrm{Mg}$ concentrations and compositional strain. The estimated $\mathrm{Mg}$ concentration and the compositional strain are shown for the four separate XRD peak reflections for the metastable Al after HPT for 100 turns and after natural aging in $(\mathbf{a}, \mathbf{b})$, respectively. The vertical dashed lines are calculated with the lattice parameter of $\alpha_{0}=4.049 \AA$ for pure $\mathrm{Al}$ in each plot.

Further evaluating the strengthened plateau behavior in the XRD line profile for the aged metastable material, and by applying Eq. (1) with arbitrarily selected counting probability, the four separate XRD peaks are visualized in Fig. $5(\mathrm{a}, \mathrm{b})$ for the metastable $\mathrm{Al}$ alloy immediately after processing and after natural aging, respectively, where the top abscissa measures the lattice deviation from pure $\mathrm{Al}$ in the total compositional strain by $\Delta a / a_{0}$ for any of the scattering vectors of the four observed reflections. This strengthened broadening confirms a heterogeneous $\mathrm{Mg}$ concentration in many different nano-scale grains of the metastable alloy. The yellow dots mark the minimum and maximum $\mathrm{Mg}$ concentrations estimated from the plots. Thus, the metastable Al alloy immediately after HPT for 100 turns contains $\mathrm{Mg}$ solute for a maximum of $\sim 40$ at.\% where this result is in excellent agreement with the direct observation of 38.44 at.\% by chemical analysis and thus the bulk nanostructured metastable Al-Mg alloy contains a supersaturation of $\mathrm{Mg}$ solutes. Furthermore, the range of the $\mathrm{Mg}$ concentration is maintained reasonably constant during natural aging in the material while the distribution shifts to stronger plateau-shaped curves.

The present results demonstrate the unexpected feasibility of forming a metastable state in a bulk engineering alloy during a nanostructuring process at room temperature to very high strains whereas the current technology of powder metallurgy and powder compaction through HPT introduces only a small volume of a metastable phase within bulk materials ${ }^{28-30}$. In practice, a metastable phase involving amorphous structure is achievable after extreme straining by ultra-severe plastic deformation though HPT on several powder mixture and ingot Mg immiscible alloys ${ }^{31}$, while no data are available for the scale and volume of the metastable phase. Thus, the present study on synthesis of a bulk nanostructured metastable alloy offers significant opportunities for future materials research.

\section{Methods}

Sample preparation and processing. Two base metals were used in this study: a commercial purity (99.5\%) Al-1050 aluminum alloy and a ZK60 magnesium alloy containing 6.0 wt.\% Zn and 0.72 wt.\% Zr. These materials were received after extrusion to rods with diameters of $10 \mathrm{~mm}$. The rods were sliced into disks with thicknesses of $\sim 1.2 \mathrm{~mm}$ and polished on both sides to produce thicknesses of $\sim 0.83 \mathrm{~mm}$. The disks were processed by HPT under quasi-constrained conditions in a monotonic torsional manner at room temperature. Two sets of $\mathrm{Al}$ and $\mathrm{Mg}$ disks were processed together by HPT with the disks piled on the depression in the lower anvil in the order of $\mathrm{Al} / \mathrm{Mg} / \mathrm{Al}$ (thus, the volume ratio of $\mathrm{Al}: \mathrm{Mg}$ is 2:1) without any special sample surface treatment ${ }^{9}$ (Illustrations are available in Extended Data Fig. 3). Specifically, when a disk sample is processed in conventional HPT, the shear strain, $\gamma$, is computed by a relationship of the form ${ }^{32,33}$ 


$$
\gamma=\frac{2 \pi N r}{h}
$$

where $N$ is the number of revolutions and $r$ and $h$ are the radius and height (or thickness) of the disk, respectively. The HPT processing was conducted under a compressive pressure of $6.0 \mathrm{GPa}$ for 100 turns at a rotational speed of $1 \mathrm{rpm}$ and thus the edge of the sample receives a maximum shear strain of $\sim 4,000$. In addition, one of the disks was taken after processing and naturally aged at room temperature for 60 days to evaluate the microstructural stability. It is reasonable to note that the median plane of the sample stack shows some material loss due to outflow between the anvils and this tends to be excessive for $\mathrm{Mg}$ thereby reducing the initial overall composition of 26 at.\% $\mathrm{Mg}$ from a volume ratio 2:1 to the observed 14.2 at. $\% \mathrm{Mg}$.

Hardness measurements. One of the HPT-processed disks was cut along the diameter and the vertical cross-sectional surfaces of two semi-circular disks were polished mechanically to mirror-like conditions. One of these surfaces was etched with Keller's etchant for microstructural observations using an optical microscope equipped with a Vickers hardness tester, Mitutoyo HM-200. The other polished surface was unetched and it was used to measure the Vickers microhardness values at intervals of $0.15 \mathrm{~mm}$ in a grid pattern with a load of $50 \mathrm{gf}$ $(0.49 \mathrm{~N})$ and a dwell time of $10 \mathrm{~s}$.

Microstructural observations. Detailed microstructural observations were conducted using TEM, JEOL JEOM-2100F, at the center and edge of the disk processed by HPT for 100 turns. The TEM specimens were prepared using a focused ion beam, FEI Quanta 3D FEG, where the samples were taken at the disk center at $r \approx 0 \mathrm{~mm}$ and at the disk edge at $r \approx 4.0 \mathrm{~mm}$, respectively, where $r$ is the radius of the disk. High-resolution compositional analysis was conducted using energy dispersive spectroscopy in a scanning TEM mode.

Texture and compositional analyses. The changes in the crystal structure, chemical compositions, lattice parameter and crystal domain size were examined with XRD analysis using a facility, Rigaku Ultima III, where the measurements integrate the data on the overall horizontal surface of the processed disk. The diffraction patterns were obtained using $\mathrm{Cu}-\mathrm{K}_{\alpha}$ radiation in a Bragg-Brentano configuration with a scanning speed of $1 \% \mathrm{~min}$ and a step size of $0.01^{\circ}$. The analytical software package MAUD ${ }^{34}$, which is based on the Rietveld method, was used to identify and quantify the amounts of compounds from these XRD profiles.

\section{Data availability}

The data supporting the findings of this study are available from the corresponding author on request.

Received: 24 June 2019; Accepted: 4 November 2019;

Published online: 20 November 2019

\section{References}

1. Valiev, R. Z. Nanostructuring of metals by severe plastic deformation for advanced properties. Nature Mater. 3, 511-516 (2004).

2. Valiev, R. Z. Large tensile elongation. Nature Mater. 12, 289-291 (2013).

3. Valiev, R. Z. et al. Fundamentals of superior properties in bulk nanoSPD materials. Mater. Res. Lett. 4, 1-21 (2016).

4. Ovid'ko, I. A., Valiev, R. Z. \& Zhu, Y. T. Review on superior strength and enhanced ductility of metallic nanomaterials. Prog. Mater. Sci. 94, 462-540 (2018).

5. Zhilyaev, A. P. \& Langdon, T. G. Using high-pressure torsion for metal processing: Fundamentals and applications. Prog. Mater. Sci. 53, 893-979 (2008)

6. Oh-ishi, K., Edalati, K., Kim, H. S., Hono, K. \& Horita, Z. High-pressure torsion for enhanced atomic diffusion and promoting solidstate reactions in the aluminum-copper system. Acta Mater. 61, 3482-3489 (2013).

7. Bouaziz, O., Kim, H. S. \& Estrin, Y. Architecturing of metal-based composites with concurrent nanostructuring: A new paradigm of materials design. Adv. Eng. Mater. 15, 336-340 (2013).

8. Qiao, X. et al. Intermetallics formed at interface of ultrafine grained $\mathrm{Al} / \mathrm{Mg}$ bi-layered disks processed by high pressure torsion at room temperature. Mater. Lett. 181, 187-190 (2016).

9. Ahn, B., Zhilyaev, A. P., Lee, H.-J., Kawasaki, M. \& Langdon, T. G. Rapid synthesis of an extra hard metal matrix nanocomposite at ambient temperature. Mater. Sci. Eng. A 635, 109-117 (2015).

10. Han, J.-K., Lee, H.-J., Jang, J.-I., Kawasaki, M. \& Langdon, T. G. Micro-mechanical and tribological properties of aluminummagnesium nanocomposites processed by high-pressure torsion. Mater. Sci. Eng. A 684, 318-327 (2017).

11. Ibrahim, N. et al. Mechanical alloying via high-pressure torsion of the immiscible Cu50Ta50 system. Mater. Sci. Eng. A 685, 19-30 (2017).

12. Han, J.-K. et al. Direct bonding of aluminum-copper metals through high-pressure torsion processing. Adv. Eng. Mater. 20, 1800642 (2018).

13. Hernández-Escobar, D., Raman, Z. U., Yilmazer, H., Kawasaki, M. \& Boehlert, C. J. Microstructural evolution and intermetallic formation in Zn-Mg hybrids processed by high-pressure torsion. Phil. Mag. 99, 557-584 (2019).

14. Kawasaki, M., Han, J.-K., Lee, D.-H., Jang, J.-I. \& Langdon, T. G. Fabrication of nanocomposites through diffusion bonding under high-pressure torsion. J. Mater. Res. 33, 2700-2710 (2018).

15. Wu, X. \& Zhu, Y. T. Heterogeneous materials: A new class of materials with unprecedented mechanical properties. Mater. Res. Lett. 5, 527-532 (2017).

16. Rogachev, S. O., Sundeev, R. V. \& Khatkevich, V. M. Evolution of the structure and strength of steel/vanadium alloy/steel hybrid material during severe plastic deformation. Mater. Lett. 173, 123-126 (2016).

17. Baricco, M., Palumbo, M., Baldissin, D., Bosco, E. \& Battezzati, L. Metastable phases and phase diagrams. La Metall. Ital. 11-12, 1-8 (2004).

18. Zhang, D. L., Massalski, T. B. \& Paruchuri, M. R. Formation of metastable and equilibrium phases during mechanical alloying of Al and Mg powders. Metall. Mater. Trans. A 25A, 73-79 (1994).

19. Scudino, S., Sakaliyska, M., Surreddi, K. B. \& Eckert, J. Mechanical alloying and milling of Al-Mg alloys. J. Alloy. Compd. 483, 2-7 (2009). 
20. Vegard, L. Die Konstitution der Mischkristalle und die Raumfüllung der Atome. Z. Physik 5, 17-26 (1921).

21. Vegard, L. \& Dale, H. VIII. Untersuchungen über Mischkristalle und Legierungen. Z. Kristallogr. 67, 148-162 (1928).

22. Luo, H. L., Chao, C. C. \& Duwez, P. Metastable solid solutions in aluminum-magnesium alloys. Trans. Metall. Soc. AIME 230, $1488-1490$ (1964).

23. Schoenitz, M. \& Dreizin, E. L. Structure and properties of Al-Mg mechanical alloys. J. Mater. Res. 18, 1827-1836 (2003).

24. Williamson, G. K. \& Hall, W. H. X-ray line broadening from filed aluminum and wolfram. Acta Metall. 1, 22-31 (1953).

25. Meier, R. J. On art and science in curve-fitting vibrational spectra. Vib. Spectrosc. 39, 266-269 (2005).

26. Thorne. A., Litzén, U. \& Johansson, S. Spectrophysics: Principles and Applications, pp. 207-208 (Springer Science \& Business Media, Berlin, Germany, 1999).

27. Hubbell, J. H. \& Seltzer, S. M. Tables of X-Ray Mass Attenuation Coefficients and Mass Energy-Absorption Coefficients from 1 keV to $20 \mathrm{MeV}$ for Elements Z $=1$ to 92 and 48 Additional Substances of Dosimetric Interest, NIST Standard Reference Database 126, version 1.4 (National Institute of Standards and Technology, Gaithersburg, MD, 2004).

28. Youssef, K. M., Scattergood, R. O., Murty, K. L. \& Koch, C. C. Nanocrystalline Al-Mg alloy with ultrahigh strength and good ductility. Scr. Mater. 54, 251-256 (2006).

29. Sauvage, X., Jessner, P., Vurpillot, F. \& Pippan, R. Nanostructure and properties of a $\mathrm{Cu}$-Cr composite processed by severe plastic deformation. Scr. Mater. 58, 1125-1128 (2008)

30. Bachmaier, A., Kerber, M., Setman, D. \& Pippan, R. The formation of supersaturated solid solutions in Fe-Cu alloys deformed by high-pressure torsion. Acta Mater. 60, 860-871 (2012).

31. Edalati, K. et al. Ultra-severe plastic deformation: Evolution of microstructure, phase transformation and hardness in immiscible magnesium-based systems. Mater. Sci. Eng. A 701, 158-166 (2017).

32. Valiev, R. Z., Ivanisenko, Y. V., Rauch, E. F. \& Baudelet, B. Structure and deformation behaviour of Armco iron subjected to severe plastic deformation. Acta Mater. 44, 4705-4712 (1996).

33. Wetscher, F., Vorhauer, A., Stock, R. \& Pippan, R. Structural refinement of low alloyed steels during severe plastic deformation. Mater. Sci. Eng. A 387-389, 809-816 (2004).

34. Lutterotti, L., Matthies, S. \& Wenk, H. R. MAUD (Material Analysis Using Diffraction): a user friendly Java program for Rietveld texture analysis and more, Proceeding of the twelfth international conference on textures of materials (ICOTOM-12), pp. 1599-1604 (NRC Research Press, Ottawa, Canada, 1999).

\section{Acknowledgements}

This study was supported in part by the National Science Foundation of the United States under Grant No. DMR1810343 and in part by the European Research Council under ERC Grant Agreement No. 267464-SPDMETALS.

\section{Author contributions}

M.K. prepared most of the manuscript. J.-K.H. performed material processing and mechanical testing and J.-K.H. and K.-D.L. conducted XRD data analysis. M.K., K.-D.L. and T.G.L. contributed to discussions on the results and interpretation of the data. All authors commented on the manuscript.

\section{Competing interests}

The authors declare no competing interests.

\section{Additional information}

Supplementary information is available for this paper at https://doi.org/10.1038/s41598-019-53614-3.

Correspondence and requests for materials should be addressed to M.K.

Reprints and permissions information is available at www.nature.com/reprints.

Publisher's note Springer Nature remains neutral with regard to jurisdictional claims in published maps and institutional affiliations.

(c) (i) Open Access This article is licensed under a Creative Commons Attribution 4.0 International License, which permits use, sharing, adaptation, distribution and reproduction in any medium or format, as long as you give appropriate credit to the original author(s) and the source, provide a link to the Creative Commons license, and indicate if changes were made. The images or other third party material in this article are included in the article's Creative Commons license, unless indicated otherwise in a credit line to the material. If material is not included in the article's Creative Commons license and your intended use is not permitted by statutory regulation or exceeds the permitted use, you will need to obtain permission directly from the copyright holder. To view a copy of this license, visit http://creativecommons.org/licenses/by/4.0/.

(C) The Author(s) 2019 